\title{
Dual motor disability in an outpatient rehabilitation center: hemiparesis after stroke and lower limb amputation patients - Who are they?
}

\section{Dupla deficiência motora em um centro de reabilitação: hemiparesia após acidente vascular cerebral e amputação de membro inferior - Quem são eles?}

\begin{abstract}
(D) Marina Portugal Makhoul ${ }^{1}$, (DKelly de Jesus Santana ${ }^{1}$, (D) Uleida de Brito Lima Lopes ${ }^{1}$, (D) Nádia Baggio Barreto Rodrigues ${ }^{1}$, DChristina de Farias Dell'Aglio ${ }^{1}$, DClarissa Barros de Oliveira ${ }^{1}$, DSheila Jean McNeill Ingham ${ }^{1}$
\end{abstract}

\begin{abstract}
Objectives: To estimate the prevalence of dual motor disability and to identify social, demographic, clinical and rehabilitation-related characteristics. Methods: Retrospective descriptive study in an outpatient rehabilitation center with individuals with dual motor disability from major lower limb amputation associated to post-stroke hemiparesis. Social demographic, clinical and rehabilitation characteristics data were collected from medical record. Results: The prevalence of dual motor disability was $5.4 \%$. Seventy-six subjects were evaluated, $69.7 \%$ were male, with a mean age of $65.6 \pm 9.3$ years. Hypertension was present in $96.1 \%$ of subjects, and $25 \%$ were smokers. Over $73 \%$ of patients had had the stroke prior to amputation. Time elapsed between lesions had a median of 23 months, and sequelae were ipsilateral in $51.3 \%$ of patients. Of these, 54 patients (71\%) were referred to physical therapy. The time interval between dual disability and the beginning of therapy was 28 months, with total rehabilitation time of 14.3 months. At rehabilitation completion, $36 \%$ achieved their goals but $30 \%$ were discharges consequent to lack of compliance. Conclusion: The prevalence of dual motor disability due to hemiparesis secondary to stroke and lower limb amputation in a rehabilitation center was $5.4 \%$. Our population showed singular characteristics related to the rehabilitation process, such as a long time between the occurrence of dual disability and the beginning of rehabilitation, and long rehabilitation period.
\end{abstract}

Keywords: Stroke, Paresis, Amputation, Rehabilitation, Epidemiology

${ }^{1}$ Associação de Assistência a Criança Deficiente AACD

Address for correspondence

Kelly de Jesus Santana

E-mail: kjs.fisio@gmail.com

Submitted: May 11, 2020

Accepted: Jul 27, 2020

\section{How to cite}

Makhoul MP, Santana KJ, Lopes UBL, Rodrigues NBB, Dell'Aglio CF, Oliveira CB, et al. Dual motor disability in an outpatient rehabilitation center: hemiparesis after stroke and lower limb amputation patients Who are they? Acta Fisiatr. 2020;27(1):45-50.

DOI: 10.11606/issn.2317-0190.v27i1a169617

\section{RESUMO}

Objetivo: Estimar a prevalência da dupla deficiência motora e identificar as características social, demográficas, clinicas e relacionadas á reabilitação desses indivíduos. Métodos: Estudo descritivo retrospectivo realizado em um centro de reabilitação com indivíduos com dupla deficiência motora decorrente de amputação de membro inferior associada à hemiparesia após acidente vascular cerebral (AVC). Características sociodemografica, clinica e relacionada a reabilitação foram coletadas através de consulta a prontuários. Resultados: A prevalência da dupla deficiência motora foi de 5,4\%. Dos 76 indivíduos avaliados, 69,7\% eram do sexo masculino, com média de idade de $65,6( \pm 9,3)$. A hipertensão arterial sistema estava presente em $96,1 \%$ dos indivíduos e $25 \%$ eram tabagistas. Mais que $73 \%$ dos pacientes tiveram o AVC prévio à amputação. 0 tempo entre as lesões foi, em mediana, de 23 meses, as sequelas foram ipsilaterais em $51,3 \%$ dos pacientes. Desses, 54 pacientes (71\%) foram encaminhados para as terapias físicas. 0 tempo entre a dupla deficiência e o início da terapia foi de 28 meses, com tempo de reabilitação total de 14,3 meses. Ao fim do processo de reabilitação $36 \%$ alcançaram suas metas, mas $30 \%$ teve alta devido a falta de adesão ao tratamento. Conclusão: A prevalência da dupla deficiência motora devido a hemiparesia após AVC e amputação de membro inferior foi 5,4\%, e a população estudada apresentou características singulares relacionada ao processo de reabilitação, como um longo tempo entre a ocorrência da dupla deficiência e o inicio da reabilitação, e um longe tempo na reabilitação.

Palavras-chave: Acidente Vascular Cerebral, Paresia, Amputação, Reabilitação, Epidemiologia 


\section{INTRODUCTION}

The presence of arterial vascular disease in one territory represents an increased risk of occurrence of a second event in other territories. ${ }^{1}$ The combination of cerebrovascular diseases and peripheral vascular diseases can result in an unfavorable physical condition with the concomitant presence of hemiparesis post-stroke and amputation often referred to as dual disability, ${ }^{2}$ in this paper it was adopted the term dual motor disability to highlight exclusively motor impairments. The prevalence of dual motor disability varies according to the region: in the United States the prevalence is estimated at $18 \%{ }^{2}$ but in other countries such as Italy, the United Kingdom and Taiwan, it can be as high as $42 \% .^{1,3-5}$ To the best of our knowledge, there is no information on the prevalence of dual motor disability in South America.

Dual motor disability has a direct impact on an individual's life, entails higher healthcare costs, and reduces the success rate of self-care and ambulation, in addition to making rehabilitation more difficult. ${ }^{1}$ In the 1960 s, prosthetic rehabilitation for individuals with both, amputation and hemiparesis, was contraindicated. ${ }^{6}$ Even with an increased number of referrals in the beginning of the 1990s, this population was less frequently referred to prosthetic rehabilitation when compared with subjects who did not have dual motor disability. ${ }^{5,7}$ Studies report hat with advances in medicine and rehabilitation, there has been a significant change in this scenario, and patients who have had a stroke and an amputation started to be admitted to rehabilitation centers more frequently, ${ }^{1-4}$ and have had satisfactory results with prosthetic rehabilitation. ${ }^{4}$

Many factors may influence the progress of rehabilitation in this population, including clinical severity and the unique characteristics of dual disability, ${ }^{3}$ and this poses a great challenge to a multidisciplinary care team. ${ }^{3-}$ ${ }^{5}$ Despite rising clinical and scientific interest about the rehabilitation of this population, dual motor disability remains under addressed.

\section{OBJECTIVE}

In this context, the objective of this study was to estimate the prevalence of dual motor disability and to identify social, demographic, clinical and rehabilitation related characteristics of these individuals in an outpatient rehabilitation clinic.

\section{METHODS}

This is a retrospective descriptive study, conforms to STROBE guidelines of information, conducted by a review of patients' charts in an outpatient rehabilitation center. Written informed consent was not obtained as this was a retrospective study and this study has been approved by the Ethics Committee of our Institution. All procedures performed involving human participants were in accordance to the ethical standards of the institutional and/ or national research committee and with the 2000 Helsinki declaration and its later amendments or comparable ethical standards.

It was included individuals with medical diagnosis of major lower limb amputation associated with post-stroke hemiparesis, admitted to an outpatient rehabilitation center in the period between 2010 and 2015. The following levels were established for lower limb amputation: transtibial, knee disarticulation and transfemoral, either unilateral or bilateral, regardless of etiology. Subjects with incomplete charts, other associated neurologic pathologies, double hemiparesis, or absence of motor sequelae were excluded.

The following social and demographic characteristics were collected in this study: gender, age (in complete years) and level of education, which was categorized into: less than one year of schooling, from one to five years, from six to nine years and more than ten years of schooling.

Clinical data regarding stroke and amputation were based on the medical diagnosis and the following information was collected: date of occurrence of lesions, amputation side, level and etiology, side of hemiparesis and number of strokes.

Associated comorbidities listed were hypertension, diabetes mellitus (DM), dyslipidemia (DLP), chronic kidney disease (CKD), chronic obstructive pulmonary disease (COPD), heart disease, visual impairment, peripheral vascular disease, seizures and/ or epilepsy. Lifestyle habits considered were drinking and smoking.

About rehabilitation process characteristics was considering the following time intervals were evaluated: time elapsed between dual motor disability and the beginning of rehabilitation, total rehabilitation time, as well as pre-prosthetic and prosthetic fitting time intervals. The type of therapy proposal was defined as following: pre-prosthetic therapy (i.e. preparing to prosthesis fitting); pre-prosthetic therapy followed by prosthetic therapy (i.e. preparing and prosthesis fitting) and rehabilitation without prosthesis (ie. rehabilitation without prosthetic goals). In addition, reasons for nonreferral of patients to physical rehabilitation were categorized as: clinical instability, patient forgoing rehabilitation and others.

The initial and final functional goals of rehabilitation for every patient were collected based the body function, activity and participation components of the International Classification of Functioning, Disability and Health (ICF), which belongs to the Family of International Classifications of the World Health Organization $(\mathrm{WHO})^{8}$ (Chart 1). The reason for patient's discharge or dropout from the rehabilitation process was categorized into: rehabilitation goals achieved, lack of compliance to treatment, clinical events/ surgical procedures, cognitive or behavioural aspects and death.

\section{Statistical Analysis}

A descriptive analysis was conducted for the clinical, social, demographic and rehabilitation-related variables aiming to identify the characteristics of the population studied. Normality analysis of the data was conducted using the Kolmogorov-Smirnov test, with numeric variables being presented as average and standard deviation (X \pm SD) when normal, or median and range when not normal. Category variables will be presented in absolute terms and/or relative frequency. The established level of significance was $5 \%$ $(p<.05)$. The Statistical Package for the Social Sciences software (SPSS version 21, Inc., Chicago, IL, USA) was used for all analysis.

\section{RESULTS}

Figure 1 demonstrates the flowchart for the processes of selection, inclusion and exclusion of patients with dual motor disability. Prevalence was estimated at 5.4\%

As for social and demographic data of the patients analyzed, it was observed that 53 $(69.7 \%)$ were male, and the mean age (SD) was 65.6 ( \pm 9.3 years). As for level of education, 11 $(14.5 \%)$ had less than one year of schooling, 27 (35.5\%) had one to five years, $36(47.3 \%)$ has six to nine years, and $2(2.6 \%)$ had more than ten years of schooling.

The clinical characteristics of dual motor disability patients are presented in Table 1 patients had a median of 1 stroke, ranging from 
Chart 1. International Classification of Functioning (ICF) categories, and initial and final functional goals of subjects with dual motor disability in a rehabilitation center

\begin{tabular}{|ll|}
\hline ICF Categories & Initial and final functional goals \\
\hline d410 & Changing and maintaining body position (kneeling, sitting, standing, bending) \\
\hline d465 & Moving around using equipment (crutches and walkers) \\
b730 & Muscle power functions \\
d420 & Transferring oneself \\
b798 & Neuromusculoskeletal and movement-related functions (stump massage, neuroma, compressive dressings) \\
d540 & Dressing \\
b710 & Mobility of joint functions \\
d415 & Maintaining basic body position (remain standing) \\
d455 & Moving around (stairs) \\
d198 & Learning and applying knowledge \\
\hline
\end{tabular}

1 to 2 . Time between lesions had a median of 23 months (average $56.9 \pm 87.5$ months) varying from 0 to 562 months (approximately 47 years). Of the 76 patients analyzed, 22 were not eligible to begin physical rehabilitation, the most frequent reason being uncontrolled medical conditions $(n=20,91 \%)$. Of the 54 (71\%) who were referred to a rehabilitation program, $34(63 \%)$ of them were referred to a complete program (pre-prosthetic and prosthetic therapy), and 20 (37\%) were referred to rehabilitation without prosthesis.

Of the 34 that initiated the complete program, $13(38.2 \%)$ did not make it to the prosthetic fitting. Nine (20\%) of patients are currently in rehabilitation. 36 patients completed the rehabilitation process.

Reasons for discharge or dropout of therapies were: goals achieved in 13 (36.1\%) of subjects, lack of compliance to treatment in $11(30.4 \%)$, clinical events during the therapy process in six $(16.6 \%)$, death in four $(11 \%)$, and cognitive/behavioural deficit, making the continuation of therapy not feasible, in two (5.5\%).

Length of stay in the pre-prosthetic rehabilitation phase was, on average, $11.7 \pm$ 7.3 months for the 30 patients who completed this phase. Only 13 patients completed the training phase with the prosthesis, with an average period of $5.8 \pm 3.8$ months. Thus, total rehabilitation time was $14.3 \pm 10.8$ months. The time interval between dual motor disability (considered since the onset of the last impairment) and the beginning of therapy was $28.6 \pm 21.1$ months. Subjects who began physical rehabilitation had their initial functional goals and their achieved goals categorized according to ICF codes that are presented in Figure 2.
This study showed the unique characteristics of patients with dual motor disability secondary to lower limb amputation and post-stroke hemiparesis who were referred to an outpatient rehabilitation center. The characteristics of this particular population are diverse and not yet broadly Established. ${ }^{1,9}$ In a systematic review, Hebert et al9 identified a prevalence variation ranging between 8 and $18 \%$. Brunelli et al. ${ }^{3}$ in 2006, reported a prevalence of $14 \%$, of patients affected by above-knee amputation and hemiparesis. In Taiwan, the prevalence found was $8.7 \%{ }^{4}$

The prevalence for dual motor disability found in our study (5.4\%) was lower than the reported in previous literature. This could be explained by several reasons: i) this population has a high incidence of mortality and the patients might have not reached the rehabilitation center. The presence of cerebrovascular disease increases mortality rate after an amputation in 2.3 times in the first 30 days and in 2.5 times in the first year10; ii) Prvu-Bettger et al. ${ }^{2}$ have shown that amputees with concomitant neurological disorders have a higher number of comorbidities than patients with only an amputation; this could also decrease the center; iii) this study was performed in a third world country in which patients have less access to Health Care and less information about Rehabilitation and this could lead to less referrals to the Rehabilitation Center; iv) in addition, Neumann et al. ${ }^{5}$ reported that stroke associated with amputation is classified as a reason for nonreferral for rehabilitation, as well as cardio-respiratory problems, cognitive

\section{DISCUSSION} presence of these subjects in a rehabilitation dysfunction, patient's unwillingness, arthritis, or the association of any of these conditions, ${ }^{5}$ in addition to the high morbidity/mortality rate of these individuals, that prevents them from getting to the rehabilitation phase $1,2,5 ; \mathrm{v}$ ) our population presented with a low level of education and it has been shown that people with higher years of schooling, have a higher ability to manage chronic health conditions. ${ }^{11}$

Average age found in the present study (65.6 \pm 9.3 years) corroborates previous ones, in which a variation of 62 to 69 years has been reported. ${ }^{1-4,12}$ Age increased leads to greater exposure to risk factors which are common to both pathologies, such as hypertension, diabetes, dyslipidemias, ${ }^{13}$ in addition to vascular alterations linked to aging itself, resulting in a higher risk of this condition occurring in the elderly. ${ }^{14}$ As for gender distribution, there were more men than women in this study, as well as in several previous studies. ${ }^{1-5,12,15}$

When the pathologies are evaluated separately, a higher prevalence of males is also noticed16, thus increasing the occurrence in dual disability. With regards to level of education, no investigation was found addressing the level of schooling of subjects with dual motor disability. However, it is known that there is a positive correlation between subjects' level of education and their health conditions, even when other social and economic factors, such as income and race, are isolated, in such a manner that an additional one year of education reduces death rate by at least 3.6 percentage points for the next 10 -year. ${ }^{11}$ Also, education provides the individual with critical thinking that is vital to improve health. ${ }^{11}$

Regarding the order in which lesions occur in dual disability, our findings corroborate those of a number of studies, $2,4,7,15$ which found a higher frequency of stroke occurring first, being followed by amputation. The presence of vascular injury in one territory is a risk factor for a second vascular event. ${ }^{1}$ Stroke, as a first lesion, generates an important impact on subjects' mobility5, which, added to old age and hemiparesis, can lead to a greater predisposition to deep venous thrombosis, which in turn can trigger a process that leads to limb amputation. ${ }^{17}$ Patients who have had a stroke prior to amputation are known to have a poorer prognosis as it relates to ambulation and rehabilitation success. ${ }^{18}$ As for time between lesions, in this investigation we found a median of 23 months between lesions, similar to findings of previous studies conducted (23 to 32 months). ${ }^{3,15,19}$ 


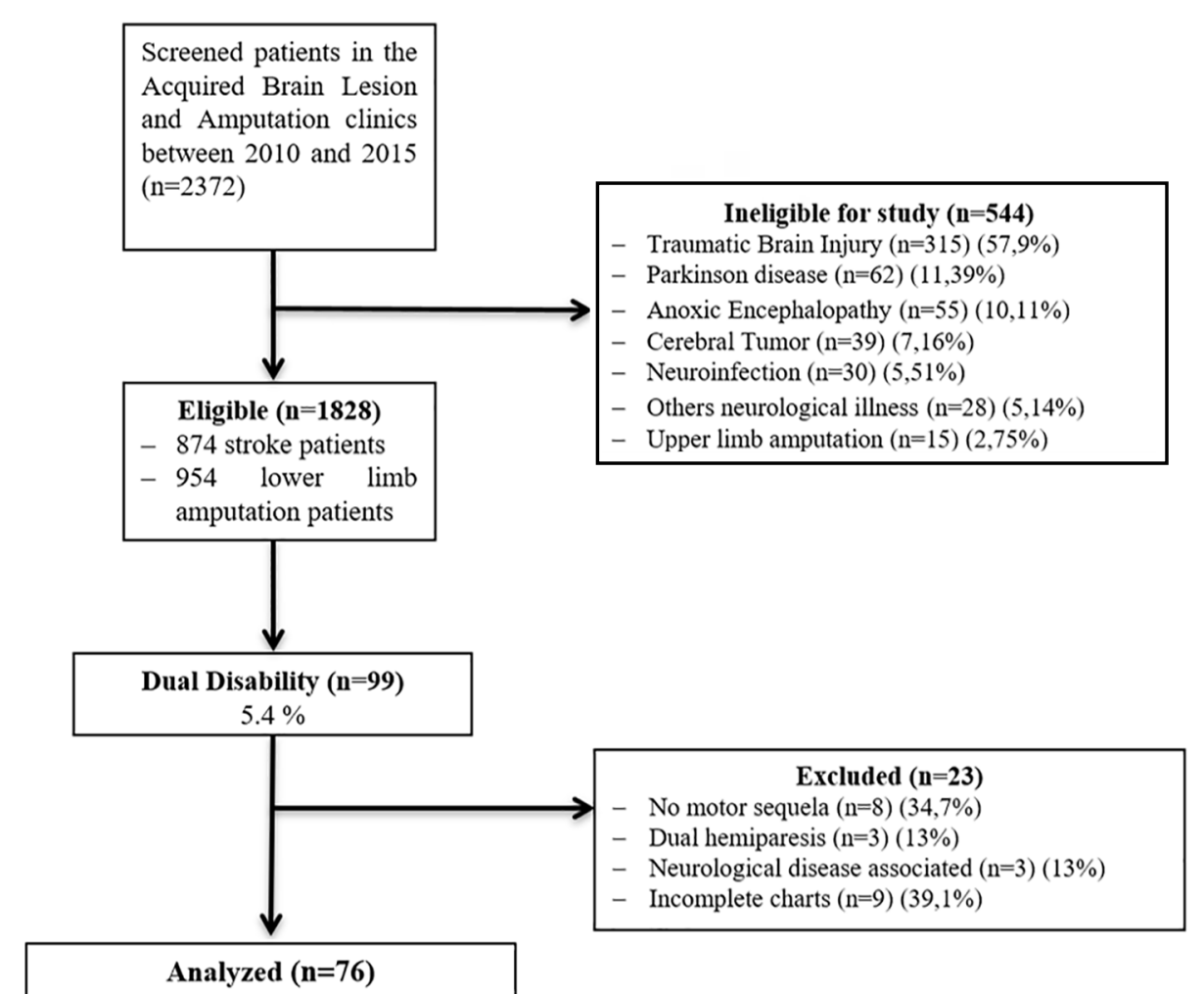

Figure 1. Flowchart of selection of subjects with dual motor disability in an outpatient rehabilitation center

Findings by Chiu et al. ${ }^{4}$ differ from the literature in that they show an average time between lesions of 4.9 years. It is known that functional status and the ability to walk after the first lesion are factors related to a better prognosis during rehabilitation. ${ }^{7}$

Among the comorbidities analyzed, hypertension, peripheral vascular disease and diabetes mellitus were the top three comorbidities seen in individuals with dual disability. Prvu-Bettge et al. $^{2}$ identified hypertension as the most frequent comorbidity, followed by congestive heart failure and anemia. Lifestyle habits as they relate to the occurrence of dual disability remain poorly studied, with the case report by Handa et al. ${ }^{15}$ to be highlighted, pointing to alcohol abuse and smoking as the main habits. In this study, we could verify that $25 \%$ of subjects were smokers, reinforcing the impact of risk factors considered to be modifiable on the occurrence of dual disability.

Given the multifactorial etiology of both lesions, we can expect a clinical profile that adds risk factors. ${ }^{16,20}$ These findings have a direct correlation with the vascular etiology, the most frequent cause of amputation found both in the present study and in previous ones. ${ }^{1,3,4}$
Laterality is one of the main prognostic factors leading to prosthesis abandonment. ${ }^{1}$ The present investigation identified ipsilateral sequelae as the most frequent, in agreement

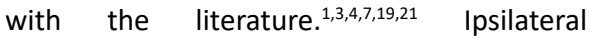
amputation and hemiparesis are recognized as one of the factors associated with a successful prosthetic rehabilitation of patients with dual disability. ${ }^{1,3,4,7}$ The condition of the remaining limb as well as the condition of the limb contralateral to the affected leg are also predictors that may influence the success of prosthetic fitting. ${ }^{22}$ Hemiparesis in the nonaffected limb may interfere negatively in patients' ability to walk. ${ }^{1,3,7}$

One of the unique characteristics of our investigation has to do with time elapsed between the patient having dual disability and beginning rehabilitation, which is, on average, 28.6 months. No previous studies reported this type of data, but the importance of an early intervention in the rehabilitation process is well known, both for postamputation rehabilitation, ${ }^{1-4}$ and for post-stroke rehabilitation, in which early intervention is a prognostic predictor of gait and independence in activities of daily living. ${ }^{23}$
In addition, in this investigation approximately $30 \%$ of the subjects were not referred to therapy and the main reason for this was an uncontrolled medical condition. It is broadly accepted that clinical conditions are an important factor influencing referral and the rehabilitation process; previous studies report that subjects amputated at the transtibial and transfemoral levels have a mortality rate over $52 \%$ within a year of amputation. ${ }^{24,25}$

In the same framework, previous studies has reported cerebral diseases as one of the factors associated with increased mortality within 30 days, and patients with cerebrovascular disease stand a 2.3-fold higher chance of dying than those without it. ${ }^{10}$ Considering the period within one year of amputation, the chance of a patient dying increases to 2.5 -fold. ${ }^{10}$ These findings point to the importance of clinical stability as a patient safety factor for the start of the rehabilitation process.

In addition to this, energy expenditure during ambulation of transtibial amputees increases by 9 to $42 \%$, while for above-knee amputees, energy expenditure increases by 82 to $125 \%,{ }^{26}$ but no one knows the impact of dual disability on energy expenditure in patients ambulating with prosthesis. Still, we can suppose that energy expenditure would be even greater leading to a higher risk of a cardiovascular event.

Subjects with dual motor disability have been improved independence in activities of daily living after rehabilitation, Moreover, it is known that these patients may benefit as specific training than in prosthetic therapy, ${ }^{1-5,7,9,12,15}$ reaffirming the importance of including this population in a rehabilitation process. In this context, the literature suggests that regaining gait, with the aid of a prosthetic device, becomes the primary goal of the rehabilitation team when working with patients with dual disability. ${ }^{1,3-5,12,15,18,21}$

In the present investigation, most referrals, were to therapies aiming at prosthetic fitting, corroborating the literature. In a previous study, ${ }^{9}$ approximately $58 \%$ of subjects with dual disability were referred to rehabilitation with a prosthetic device, with $70-80 \%$ of them maintaining gait one year after rehabilitation. ${ }^{9}$ Factors correlated with success in prosthetic rehabilitation and gait of patients with dual disability are: amputation and ipsilateral hemiparesis, transtibial amputation and the absence of cognitive sequelae. ${ }^{1,3,5,7}$

The success of prosthetic rehabilitation is closely related to the phase prior to acquisition of the prosthetic device, with the need to 
Table 1. Clinical characteristics of subjects with dual motor disability in an outpatient rehabilitation center

\begin{tabular}{|c|c|c|}
\hline & & $\mathbf{N}(\%)$ \\
\hline \multirow{5}{*}{ Amputation side } & Right & $32(42.1)$ \\
\hline & Left & $33(43.4)$ \\
\hline & Bilateral & $11(14.5)$ \\
\hline & Transtibial & $16(21.1)$ \\
\hline & Transfemoral & $49(64.5)$ \\
\hline \multirow{5}{*}{ Amputation level } & Transtibial $R$ and transtibial $L$ & $2(2.6)$ \\
\hline & Transtibial R and transfemoral L & $3(3.9)$ \\
\hline & Transfemoral R and transfemoral L & $4(5.3)$ \\
\hline & Transfemoral R and transtibial $\mathrm{L}$ & $2(2.6)$ \\
\hline & Vascular & $72(94.7)$ \\
\hline \multirow{3}{*}{ Amputation etiology } & Infectious & $2(2.6)$ \\
\hline & Traumatic & $2(2.6)$ \\
\hline & Right & $41(53.9)$ \\
\hline \multirow{2}{*}{ Hemiparesis side } & Left & $35(46.1)$ \\
\hline & Stroke-Amputation & $56(73.7)$ \\
\hline \multirow{3}{*}{ Order of occurrence } & Amputation-Stroke & $17(22.4)$ \\
\hline & Simultaneous & $3(3.9)$ \\
\hline & Ipsilateral & $39(51.3)$ \\
\hline \multirow{6}{*}{ Laterality of sequelae } & Contralateral & $26(34.2)$ \\
\hline & Bilateral & $11(14.5)$ \\
\hline & Hypertension & $73(96.1)$ \\
\hline & Peripheral vascular disease & $62(81.6)$ \\
\hline & Diabetes Mellitus & $46(60.5)$ \\
\hline & Dyslipidemia & $34(44.7)$ \\
\hline \multirow{6}{*}{ Comorbidities } & Heart disease & $32(42.1)$ \\
\hline & Chronic renal failure & $6(7.9)$ \\
\hline & COPD & $3(3.9)$ \\
\hline & Visual impairment & $3(3.9)$ \\
\hline & Seizures/Epilepsy & $2(2.6)$ \\
\hline & Alcohol consumption & $9(11.8)$ \\
\hline Lifestyle habits & Smoking & $19(25.0)$ \\
\hline
\end{tabular}

prepare and explore the subject's maximum capacity in the pre-prosthetic phase. ${ }^{27}$ General conditioning, cardiovascular endurance, adequate muscle strength and range of motion, management of the non-affected limb, and standing balance are all factors which contribute positively to a fitting of a prosthetic device. $^{27,28}$

Patients with chronic diseases are frequently physically unfit due to reduced mobility and several comorbidities present. Consequently, they present functional dependence and dependence in activities of daily living, muscle weakness, balance deficit, and stroke-related deformities. In this context, the most frequent initial goals, based on ICF, are geared to primary aspects, such as stump massage, desensitization of a painful neuroma, functions related to muscle power and patient and family education.

To the best of our knowledge, no studies have used ICF to set the goals for rehabilitations in this dual disability population. It was opted for the use of ICF as the World Health
Organization report on disability considers the ICF as a universal landmark, and recommends its use both for research purposes and as a clinical and functional approach in disabilities. ${ }^{29}$

Other frequent goals were related to transferring oneself from one surface to another and changing basic body positions, such as kneeling, sitting, standing up and bending. The high frequency of goals considered to be basic in the prosthetic rehabilitation phase may be justified due to clinical and cognitive factors present in these individuals.

It is known that transfemoral amputation, old age, cognitive function deterioration, clinical and psychosocial status, as well as diabetes, are factors that negatively influence rehabilitation, impacting patients' motor learning ability and the acquisition of new skills. ${ }^{1-5}$ The vascular etiology is closely related to cognitive alterations, mainly executive functions. ${ }^{30}$ And so, gait becomes no longer the primary goal, and moving around with equipment and transferring become more important. ${ }^{27}$

In the present study, only $36.1 \%$ of patients were discharged from rehabilitation because they achieved the goals proposed by the multidisciplinary team. Unfortunately, another frequent reason for patients to discontinue rehabilitation was the lack of compliance to treatment (30.4\%). Rehabilitation treatment maintenance is associated with social, economic and emotional factors, requiring a network of care around the patient. ${ }^{29}$ Factors such as lack of transportation, absence of a companion, clinical instability and motivational factors can make the rehabilitation process unfeasible. ${ }^{29}$

In this study, rehabilitation time was shown to be approximately six times longer than that reported by Brunelli et al. ${ }^{1,3}$ and five times longer than that reported by Chiu et al. ${ }^{4}$ A longer length of stay in specialized centers increases public spending and leads to changes in the family routine. ${ }^{29}$

The long length of stay of these subjects may be associated with the characteristics of dual disability presented in this study, such as amputation at the transfemoral level, longer time to begin rehabilitation (leading to increased osteo-articular and muscular complications, and cardiovascular unfitness) and all consequences resulting from immobilization; all these factors could lead to a longer length of stay at our rehabilitation center.

The knowledge about subjects with dual motor disability is an important field which concern both scientific and clinical domains in order to provide an appropriate approach to this population which can benefit from rehabilitation. Our study was limited by its retrospective nature that implied all the known biases and limitations such as: missing data and variable assessment carried out by various examiners. The studied population is very specific, and this study presented a small sample size. Hence, we consider that a larger number of individuals could allow to perform a deeper analysis specially concerning the influence of sociodemographic and clinical characteristics on the rehabilitation process.

\section{CONCLUSION}

The prevalence of dual motor disability due to hemiparesis secondary to stroke and amputation of lower limbs in a rehabilitation center is $5.4 \%$. Our population showed singular characteristics related to rehabilitation process, such as long time between the occurrence of dual disability and the beginning of rehabilitation, and long stay in this process. 


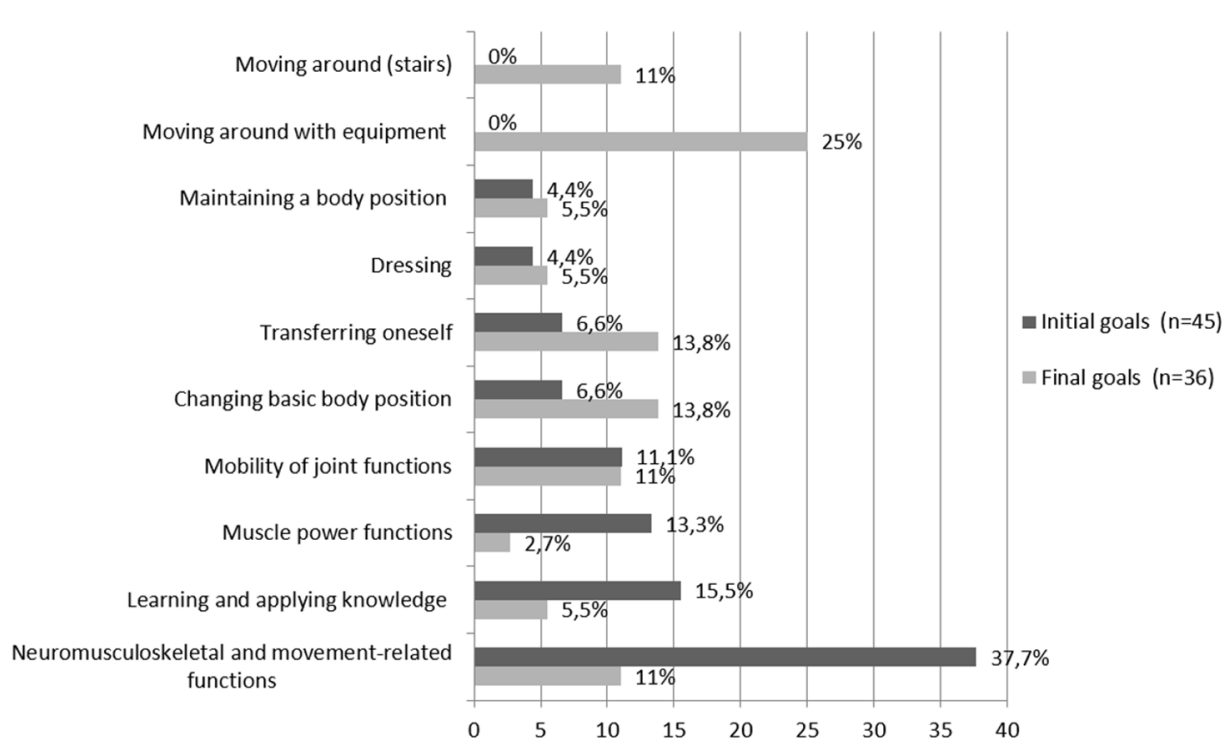

Figure 2. Initial and final goals of rehabilitation for subjects with dual motor disability in an outpatient rehabilitation center

\section{REFERENCES}

1. Brunelli S, Fusco A, losa M, Delusso AS, Paolucci S, Traballesi M. Mid- to long-term factors influencing functional status of people affected by lower-limb amputation associated with hemiparesis due to stroke. Disabil Rehabil. 2013;35(12):982-9. Doi: https://doi.org/10.3109/09638288.2012.717583

2. Prvu-Bettger JA, Bates $B E$, Bidelspach $D E$, Stinemam MG. Short- and long-term prognosis among veterans with neurological disorders and subsequent lower-extremity amputation. Neuroepidemiology. 2009;32(1):4-10. Doi: https:// doi.org/10.1159/000170085

3. Brunelli S, Averna T, Porcacchia P, Di Meo F, Trabalessi M. Functional status and factors influencing the rehabilitation outcome of people affected by aboveknee amputation and hemiparesis. Arch Phys Med Rehabil. 2006;87(7):995-1000. Doi: https://doi. org/10.1016/j.apmr.2006.04.004

4. Chiu CC, Chen CE, Wang TG, Lin CM, Lien IN. Influencing factors and ambulation outcome in patients with dual disabilities of hemiplegia and amputation. Arch Phys Med Rehabil. 2000;81(1):14-7. Doi: https://doi. org/10.1016/S0003-9993(00)90214-4

5. Neumann VC, Cotter DH, Geddes JM, Waxan R. The influence of prior stroke on the prosthetic rehabilitation of lower limb amputees. Prosthet Orthot Int. 1998;22(2):102-6. Doi: https://doi. org/10.3109/03093649809164470

6. Hoover RM. Problems and complications of amputees. Clin Orthop Relat Res.1964;37:47-52. Doi: https://doi.org/10.1097/00003086-19641100000007

7. OConnel PG, Gnatz S. Hemiplegia and amputation: rehabilitation in the dual disability. Arch Phys Med Rehabil. 1989;70(6):451-4. Doi: https://doi. org/10.1016/0003-9993(89)90005-1
8. World Health Organization. ICF - International Classification of Functioning, Disability and Health. Geneva: World Health Organization; 2001.

9. Hebert JS, Payne MWC, Wolfe DL, Deathe AB, Devlin $M$. Comorbidities in amputation: a systematic review of hemiplegia and lower limb amputation. Disabil Rehabil. 2012;34(23):1943-1949. Doi: https://doi.or g/10.3109/09638288.2012.665131

10. Fortington LV, Geertzen JH, Van Netten JJ, Postema $\mathrm{K}$, Rommers GM, Dijkstra PU. Short and long term mortality rates after a lower limb amputation. Eur $J$ Vasc Endovasc Surg.2013;46(1):124-131. Doi: https:// doi.org/10.1016/j.ejvs.2013.03.024

11. Lleras-Muney A. The relationship between education and adult mortality in the United States. Rev Econ Stud. 2005;72(1):189-221. Doi: https://doi. org/10.1111/0034-6527.00329

12. Ishii M, Yamanaka T. Leg orthosis treatment for a patient with left parietal foot amputation and right hemiplegia. Top Stroke Rehabil. 2004;11(3):16-18. Doi: https://doi.org/10.1310/TQMA-PAWW-TD49-CHWB

13. World Health Organization. World health statistics 2016: monitoring health for the sustainable development goals. Geneva: WHO; 2016.

14. Marengoni A, Angleman S, Melis R, Mangialasche F, Karp A, Garmen A, et al. Aging with multimorbidity: a systematic review of the literature. Ageing Res Rev. 2011;10(4):430-9. Doi: https://doi.org/10.1016/j. arr.2011.03.003

15. Handa G, Singh U. Multiple vasculogenic disabilities: a challenge in rehabilitation. Neurol. India. 2001;49(1):84-6.

16. Mozaffarian D, Benjamin EJ, Go AS, Arnett DK, Blaha MJ, Cushman M, et al. Heart disease and stroke statistics-2016 update: a report from the American Heart Association. Circulation. 2016;133(4):e38-360. Doi: https://doi.org/10.1161/ CIR.0000000000000350
17. Kong KH, Chua SG, Earnest A. Deep vein thrombosis in stroke patients admitted to a rehabilitation unit in Singapore. Int J Stroke. 2009;4(3):175-9. Doi: https:// doi.org/10.1111/j.1747-4949.2009.00278.x

18. Altner PC, Rockley P, Kirby K. Hemiplegia and lower extremity amputation: double disability. Arch Phys Med Rehabil. 1987;68(6):378-9.

19. Garrison JH, Shankara B, Mueller MJ. Stroke hemiplegia and subsequent lower extremity amputation: which side is at risk? Arch Phys Med Rehabil. 1986;67(3):187-9. Doi: https://doi.org/10.1016/00039993(86)90082-1

20. Kayssi A, de Mestral C, Forbes TL, Roche-Nagle G. A Canadian population-based description of the indications for lower-extremity amputations and outcomes. Can J Surg. 2016;59(2):99-106. Doi: https://doi.org/10.1503/cjs.013115

21. Varghese $G$, Hinterbuchner $C$, Mondall P, Sakuma J. Rehabilitation outcome of patients with dual disability of hemiplegia and amputation. Arch Phys Med Rehabil. 1978;59(3):121-3.

22. Schaffalitzky E, Gallagher P, Maclachlan M, Weggener ST. Developing consensus on important factors associated with lower limb prosthetic prescription and use. Disabil. Rehabil. 2012;34(24):2085-94. Doi: https://doi.org/10.3109/09638288.2012.671885

23. Veerbeek J, van Wengen E, van Peppen RPS, Hendriks EJM, Rietberg MB, van der Wees PJ, et al. KNGF Clinical Practice Guideline for Physical Therapy in patients with stroke. Amersfoort: Royal Dutch Society for Physical Therapy - KNGF; 2014.

24. Remes $L$, Isoaho $R$, Vahlberg $T$, Hiekkanen $H$, Korhonen $\mathrm{K}$, Vitanen $\mathrm{M}$, et al. Major lower extremity amputation in elderly patients with peripheral arterial disease: incidence and survival rates. Aging Clin Exp Res. 2008;20(5):385-93. Doi: https://doi.org/10.1007/BF03325142

25. Eskelinen $E$, Lepantalo $M$, Hietala EM, Sell $H$, Maenpaa I, Pitkanen J, et al. Lower limb amputations in Southern Finland in 2000 and trends up to 2001. Eur J Vasc Endovasc Surg. 2004;27(2):193-200. Doi: https://doi.org/10.1016/j.ejvs.2003.10.011

26. Hunter D, Cole SE, Murray JM, Murray TD. Energy expenditure of below-knee amputees during harness-supported treadmill ambulation. J Orthop Sports Phys Ther. 1995;21(5):268-76. Doi: https:// doi.org/10.2519/jospt.1995.21.5.268

27. Sansam K, O'Connor RJ, Neumann V, Bhakta B. Clinicians' perspectives on decision making in lower limb amputee rehabilitation. J Rehabil Med. 2014;46(5):447-53. Doi: https://doi. org/10.2340/16501977-1791

28. Gailey RS, Wenger MA, Raya M, Kirk N, Erbs K, Spyropoulos $\mathrm{P}$, et al. Energy expenditure of transtibial amputees during ambulation at self-selected pace. Prosthet Orthot Int. 1994;18(2):84-91. Doi: https://doi.org/10.3109/03093649409164389

29. World Report on Disability. Lancet. 2011;377(9782):1977.Doi: https://doi. org/10.1016/S0140-6736(11)60844-1

30. O'Neill BF, Evans JJ. Memory and executive function predict mobility rehabilitation outcome after lower-limb amputation. Disabil Rehabil. 2009;31(13):1083-91. Doi: https://doi. org/10.1080/09638280802509579 